\title{
Importância dos materiais cerâmicos na nossa sociedade
}

\footnotetext{
${ }^{1}$ Subeditor de Advanced Ceramic Materials

Laboratório de Materiais e Pilha a Combustível - LaMPaC, Universidade Federal de Minas Gerais / Departamento de Química, Av. Antonio Carlos, 6627 - Pampulha, Caixa Postal Química: 702 - CEP: 31270-901, Belo Horizonte, MG, Brazil.

tmatencio@ufmg.br
}

Podemos considerar que existem atualmente na ciência de materiais quatro tipos de materiais: os metais e as ligas, os polímeros, as cerâmicas e os compósitos [1] [2]. Para maioria das pessoas a palavra cerâmica está somente relacionada com material de construção (cimento, tijolos, revestimento de piso ou parede) e louça. Efetivamente, os mais antigos traços de materiais cerâmicos são fragmentos de louças, a base de argila, elaboradas na china pré-histórica. Esse tipo de cerâmica, que faz parte das cerâmicas chamadas tradicionais, são constituídas principalmente de silicatos, que são compostos combinados de dióxido de silício $\mathrm{SiO}_{2}$, e de outros óxidos metálicos tais como $\mathrm{Al}_{2} \mathrm{O}_{3}, \mathrm{CaO}, \mathrm{K}_{2} \mathrm{O}$ ou $\mathrm{MgO}$. A partir da metade do século passado, com o desenvolvimento tecnológico de novos processos de elaboração e caracterização, materiais cerâmicos inovadores, chamados cerâmicas avançadas ou de engenharia, começaram a serem desenvolvidos, aumentando consideravelmente a área de aplicações desses materiais. Enquanto as cerâmicas tradicionais são fabricadas a partir de materiais naturais, geralmente com argila, quartzo e feldspato, as cerâmicas avançadas não possuem silicatos e são elaboradas a partir de pós sintéticos de óxidos, de nitretos, de carbetos, de boretos, de carbonetos etc. Essas últimas possuem propriedades químicas, físicas e mecânicas muito superiores às cerâmicas tradicionais, como biocompatibilidade, alta dureza, altas resistências mecânica, térmica, resistência ao desgaste e à corrosão, etc. As cerâmicas avançadas são materiais utilizados na fabricação de muitos produtos de alta tecnologia [3] [4] [5] [6], que possuem aplicações na área da saúde, como as biocerâmicas [6] [7] [8], na área da eletrônica, como as cerâmicas funcionais (eletrocerâmicas, cerâmicas magnéticas e cerâmicas óticas) [3] [4] [6] [9] [10], na conversão e estocagem de energia, como materiais de eletrodos, eletrólitos, selantes e interconectores [3] [6] [9] [11] [12]. Elas estão presentes também nas indústrias eletrodoméstica, automotiva, naval e aeronáutica devido principalmente às suas propriedades térmicas e mecânicas [3] [10]. A ciência e a tecnologia dos materiais cerâmicos são essenciais no desenvolvimento da nossa sociedade e as pesquisas nessa área tem um papel fundamental, como ilustrado na tabela 1 , que apresenta alguns dos principais tópicos atualmente investigados internacionalmente [13].

Convidamos os leitores a consultar a nova edição da revista Revista Matéria -Rio de Janeiro, na qual continuamos nossa contribuição na área dos materiais cerâmicos com a divulgação de artigos de qualidades apresentando pesquisas atuais sobre o tema.

Tabela 1: Ciência e a tecnologia dos materiais cerâmicos: principais tópicos pesquisados atualmente [13]

\begin{tabular}{c|c|c|c|c|c|c}
\hline $\begin{array}{c}\text { Novos } \\
\text { processos de } \\
\text { síntese }\end{array}$ & $\begin{array}{c}\text { Novos } \\
\text { processos } \\
\text { de } \\
\text { sinterização }\end{array}$ & Modelagem & $\begin{array}{c}\text { Bio } \\
\text { cerâmica }\end{array}$ & $\begin{array}{c}\text { Cerâmica } \\
\text { Funcional }\end{array}$ & $\begin{array}{c}\text { Conversão } \\
\text { Estocagem da } \\
\text { energia }\end{array}$ & $\begin{array}{c}\text { Cerâmica } \\
\text { tradicional }\end{array}$ \\
\hline $\begin{array}{c}\text { Hidro } \\
\text { térmico }\end{array}$ & $\begin{array}{c}\text { Assistida por } \\
\text { pressão }\end{array}$ & $\begin{array}{c}\text { Simulação } \\
\text { design }\end{array}$ & $\begin{array}{c}\text { Bio } \\
\text { materiais } \\
\text { ativos }\end{array}$ & $\begin{array}{c}\text { Condutores } \\
\text { Eletrônicos } \\
\text { Iônicos }\end{array}$ & $\begin{array}{c}\text { Solar } \\
\text { Fotovoltaico } \\
\text { Fotocatalítico }\end{array}$ & $\begin{array}{c}\text { Geo- } \\
\text { polímeros } \\
\text { Cimentos }\end{array}$ \\
\hline Micro-ondas & Micro-ondas & $\begin{array}{c}\text { Micro-estruturas } \\
\text { 3D }\end{array}$ & $\begin{array}{c}\text { Compósitos } \\
\text { híbridos }\end{array}$ & Resistores & Fusão nuclear & $\begin{array}{c}\text { Vidros } \\
\text { Esmaltes }\end{array}$ \\
\hline Laser & Laser & $\begin{array}{c}\text { Reologia } \\
\text { computacional }\end{array}$ & $\begin{array}{c}\text { Nano- } \\
\text { materiais } \\
\text { magnéticos }\end{array}$ & $\begin{array}{c}\text { Dielétricos } \\
\text { Piezoelétricos } \\
\text { Eletro- } \\
\text { magnéticos }\end{array}$ & $\begin{array}{c}\text { Baterias } \\
\text { Super- } \\
\text { capacitores } \\
\text { Pilha a } \\
\text { combustível }\end{array}$ & Tintas \\
\hline
\end{tabular}




\begin{tabular}{c|c|c|c|c|c|c}
\hline Plasma & A frio & Calibração & $\begin{array}{c}\text { Bio- } \\
\text { materiais } \\
\text { injetáveis }\end{array}$ & $\begin{array}{c}\text { Ferro- } \\
\text { elétricos }\end{array}$ & $\begin{array}{c}\text { Captura } \\
\text { de } \\
\text { carbono }\end{array}$ & $\begin{array}{c}\text { Material de } \\
\text { construção }\end{array}$ \\
\hline Sol-gel & Infravermelho & Validação & $\begin{array}{c}\text { Liberação } \\
\text { controlada }\end{array}$ & Piroelétricos & Termo-elétrico & $\begin{array}{c}\text { Cerâmicas } \\
\text { industriais }\end{array}$ \\
\hline
\end{tabular}

\section{BIBLIOGRAPHY}

[1] FANTOZZI, G., "Welcome to Ceramics: A New Open Access Scientific Journal on Ceramics Science and Engineering", Ceramics, pp. 1-2, 2018.

[2] CALliSTER, W.,J., RETHWISCH, D., Fundamentals of Materials Science and Engineering: AN INTEGRATED APPROACH, 5th Edition, Wiley, 2015.

[3] SOMIYA, S., Handbook of Advanced Ceramics. Materials, Applications, Processing and Properties, Academic Press, Elsevier, 2013.

[4] SOMIYA, S., ALDINGER, F., SPRIGGS, R., et al., Handbook of Advanced Ceramics - Volume II: Processing and their Applications, Academic Press, Elsevier, 2003.

[5] CHANDAN, B., DAS, S., Advanced Ceramic Membranes and Applications, CRC Press, 2017.

[6] OTITOJU, A. "Advanced ceramic components: Materials, fabrication, and applications", J. Ind. Eng., 2020.

[7] DA COSTA E SILVA, R., LARA, L., LOPEZ, R., et al., "Preparation of Magnetoliposomes with a Green, Low-Cost, Fast and ScalableMethodology and Activity Study against S. aureus and C. freundii Bacterial Strains", J. Braz. Chem. Soc., v. 29, n. 12, pp. 2636-2645, 2018.

[8] GUL, H., KHAN, M., KHAN, A., Bioceramics. Handbook of Ionic Substituted Hydroxyapatites, 2020.

[9] FLORIO, D.Z.D., MUCILLO, E.N., FONSECA, F., et al., "Electroceramics VI", In: Selected, peer reviewed papers from the 6th International Conference on Electroceramics (ICHSM 2010), João Pessoa, 2013.

[10] PANDEY, R.,K., Fundamentals of Electroceramics: Materials, Devices and Applications, Wiley, 2019.

[11] TARÔCO, H. A., DE PAULA ANDRADE, S., BRANT, M., et al., "Montagem e caracterização elétrica de pilhas a combustível de óxido sólido (Pacos)", Quimica Nova, v. 32, n. 5, pp. 1297-1305, 2009.

[12] FERNANDES, M., DE PAULA ANDRADE, S., BISTRITZKI, V., et al.,"SOFC-APU systems for aircraft: A review”, International Journal Of Hydrogen Energy, v. 43, pp. 16311 -16333, 2018.

[13] EUROPEAN CERAMIC SOCIETY (ECerS) - Torino - Italia, In: XVI ECerS conference, 16-20 June, 2019. [Online]. Available: https://www.ecers2019.org/. [Access in 2020].

\section{ORCID}

Tulio Matencio

https://orcid.org/0000-0002-5660-8125 